\title{
Tooth malposition in patients with cleft lip and/or palate in a Bra-
}

\section{zilian population}

\author{
Mário Rodrigues Melo Filho ${ }^{1}$, Verônica Oliveira Dias ${ }^{1}$, Daniella Reis Barbosa Martelli ${ }^{1}$, Lívia Ribeiro Paranaíba ${ }^{1}$, Mário Sérgio Oliveira Swerts $^{2}$, \\ Letízia Monteiro de Barros ${ }^{2}$, Hercílio Martelli Júnior ${ }^{1,2}$ \\ ${ }^{1}$ Stomatology Clinic, Dental School, State University of Montes Claros, Montes Claros, Minas Gerais, Brazil
${ }^{2}$ Center for the Rehabilitation of Craniofacial Anomalies, José do Rosário Vellano University, Alfenas, Minas Gerais, Brazil
}

\section{Abstract}

The purpose of the present study was to evaluate the prevalence of teeth malposition (rotated) in Brazilian patients with oral clefts and to contribute to the definition of subphenotypes. This study included 317 patients with nonsyndromic cleft lip with or without cleft palate. Tooth malposition was assessed clinically, through radiographs, and medical history records for each individual. Only teeth malpositions outside the area of the clefts were included. Comparisons were assessed by cross-tabulation and standard chi-square test, and statistical significance was set at $p \leq 0.05$. Cleft lip and palate was more prevalent in males, while cleft palate was more common in females. Regarding the presence of tooth malposition, of the 317 patients, $92(29.02 \%)$ had at least one tooth with the dental anomaly. Tooth malposition was more common in patients with cleft lip and palate $(16.1 \%)$, followed by, respectively, cleft palate (6.9\%) and cleft lip (6\%) $(p=0.112)$. The highest occurrence of tooth malposition was in the mandible and involved the canines $(p<0.01)$. Few studies have investigated the prevalence of tooth malposition in individuals with nonsyndromic cleft lip with or without cleft palate. Our results confirmed the highest occurrence of dental anomalies, particularly tooth malposition, in patients with oral clefts. Our findings also highlight that there was a higher occurrence of this condition in the mandible and not the maxilla.
Citation: Filho M, Dias V, Martelli D, Parnaiba L, Swerts M, de Barros L, Júnior H. (2015) Tooth malposition in patients with cleft lip and/or palate in a Brazilian population. Dentistry 3000 . 1:a001 doi:10.5195/d3000.2015.38

Received: July 6, 2015

Accepted: September 13, 2015

Published: October 23, 2015

Copyright: C2015 Carlini J, Severo D, Asami K. This is an open access article licensed under a Creative Commons Attribution Work 4.0 United States License.

Email: mariomelo@gmail.com

\section{Introduction}

The embryological development of the face relies on the interplay of a vast range of factors encompassing cell differentiation, growth, apoptosis, cell to cell adhesion, and inter and intracellular signaling. The disruption of a gene that controls one or more of these factors, inhibition of cell function by environmental teratogens or a combination of the two is likely to be the etiological cause of craniofacial malformations such as nonsyndromic cleft lip with or without cleft palate (NSCL/P) [1].

NSCL/P affects approximately $1 / 700$ live births, with wide variability across geographic origin, racial and ethnic groups, as well as environmental exposures and socioeconomic status. In general, Asian and Amerindian populations have the highest reported birth prevalence rates, often as high as $1 / 500$, European-derived populations have intermediate prevalence rates at about $1 / 1,000$, and African-derived populations have the lowest prevalence rates at about $1 / 2,500$ [2]. In Brazil, the prevalence is between 0.36 and 1.54 per 1,000 live births. Cleft lip and palate (CLP) is most frequent in males and isolated cleft palate (CP) is most typical in females [3]. Individuals with CLP may experience problems with feeding, speaking, hearing and social integration that can be corrected to varying degrees by surgery, dental treatment, speech therapy and psychosocial intervention [2]. It has been proposed that clefting is part of a complex malformation associated with other dental anomalies resulting from a disturbed dentition development [4]. Recent studies proposed that dental anomalies outside of the cleft area could serve as clinical markers for the definition of cleft subphenotypes, suggesting a common genetic background between such conditions [5-9]. In favor of this hypothesis is the fact that tooth, lip, and palate development occur almost concomitantly and are related anatomically [10-12]. When compared with the general population, dental anomalies, such (cc) BY ULLS D-Sorle
New articles in this journal are licensed under a Creative Commons Attribution 4.0 United States License.

This journal is published by the University Library System, University of Pittsburgh as part of its D-Scribe Digital Publishing Program and is cosponored by the University of Pittsburgh Press. 
as tooth agenesis, supernumerary teeth, microdontia, fused teeth, ectopic eruption, tooth malposition (rotation), taurodontism and enamel hypoplasia, are considerably more prevalent in individuals with NSCL/P [5-8,13-15]. In addition, few studies have investigated the dental anomalies associated with
Teeth were assessed clinically, through panoramic radiographs, and medical history records for each individual. The radiographs were examined with magnifying glass in a dark room over a light box that had a frame to avoid light passing on the sides of the radiograph. Eruption of any tooth in an abnor- using the statistical program SPSS ${ }^{\circledR}$ version 19.0 (Statistical Package for Social Sciences for Windows, Inc., USA). Comparisons were assessed by cross-tabulation and standard chi-square test, and statistical significance was set to $\mathrm{p} \leq 0.05$. This study was approved by the University's Ethics Committee in Research.

\section{Table 1. Distribution of cleft lip and/or palate according to extension and gender.}

\begin{tabular}{|c|c|c|c|c|c|c|c|c|}
\hline \multirow{2}{*}{ Gender } & \multirow{2}{*}{$\mathbf{n}$} & \multicolumn{2}{|c|}{ Cleft Lip and Palate } & \multicolumn{2}{|c|}{ Cleft Lip } & \multicolumn{2}{|c|}{ Cleft Palate } & \multirow{2}{*}{$p$ value $\left(x^{2}\right)$} \\
\hline & & $\mathbf{n}$ & $\%$ & $\mathbf{n}$ & $\%$ & $\mathbf{n}$ & $\%$ & \\
\hline Male & 172 & 112 & 35.3 & 37 & 11.7 & 23 & 7.3 & 0.067 \\
\hline Female & 145 & 77 & 24.3 & 37 & 11.7 & 31 & 9.7 & \\
\hline Total & 317 & 189 & 59.6 & 74 & 23.4 & 54 & 17.0 & \\
\hline
\end{tabular}

subphenotypes of oral clefts, justifying the importance of this study. Tooth malposition (rotation or inclination), was considered subjectively as any evident (at least $20^{\circ}$ ) mesiolingual or distolingual intraalveolar displacement of a tooth around its longitudinal axis [16]. The purpose of the present study was to evaluate the prevalence of tooth malposition in patients with oral clefts and to contribute to the definition of NSCL/P subphenotypes.

\section{Material and Methods}

This study included 317 patients with repaired NSCL/P. All participants were recruited from the same institution (Centre for Rehabilitation of Craniofacial Anomalies, Minas Gerais State, Brazil). All subjects were from Minas Gerais, Brazil, where there is an admixed population of Europeans (mostly from Portugal and Italy) and Africans, with a small percentage of native Brazilian Indians. All patients presented similar ethnicities and social culture. mal position was the criteria considered to represent malposition. Patients with a history of dental extraction, previous orthodontic treatment, or who were younger than 12 years old were excluded due to the inability to accurately identify all anomalies. In order to eliminate inter-examiner differences, dental anomalies were classified by a single calibrated examiner (intra-examiner Kappa value $=$ 0.93). We did not include primary dentition nor third molars. Only teeth malposition outside the area of the clefts were included in this study.

The clefts were categorized into three groups with the incisive foramen as a reference: (1) Cleft Lip (CL): includes complete or incomplete pre-foramen clefts, either unilateral or bilateral; (2) Cleft Lip and Palate (CLP): includes unilateral or bilateral transforamen clefts and pre- or post-foramen clefts; (3) Cleft Palate (CP): includes all postforamen clefts, complete or incomplete [17]. Median or rare clefts were not included in our analysis. The information collected was stored in a database and analyzed
Of the 317 subjects included in this study, 172 were male and 145 were female. The average age was 17.48 years old. Table 1 shows the distribution of the types of oral clefts according to extension and gender. Of the 317 patients with clefts, 189 had CLP, 74 had CL, and 54 had isolated CP. CLP was more prevalent in males, while CP was more common in females. CL had a similar distribution between the genders. With regard to skin color, most of the patients were nonCaucasian $(209,65.93 \%$; 108 or $34.06 \%$ were Caucasian).

Regarding the presence of tooth malposition, of the 317 patients, $92(29.02 \%)$ had at least one tooth with the dental anomaly. Of these 92 patients with tooth malposition, 144 teeth presented the anomaly. This means that 40 patients had more than one tooth with malposition. Table 2 shows the frequency of patients with tooth malposition according to the types of oral clefts. It turns out that tooth malposition was more common in patients with CLP (16.1\%), followed 
Table 2. Frequency of patients with tooth malposition according to the types of oral clefts.

\begin{tabular}{|l|c|c|c|c|c|c|}
\hline \multirow{2}{*}{ Type of cleft } & \multicolumn{9}{c|}{ Tooth malposition } \\
\cline { 2 - 7 } & \multicolumn{2}{|c|}{ Present } & \multicolumn{2}{c|}{ Absent } & \multicolumn{2}{c|}{ Total } \\
\cline { 2 - 7 } & $\mathbf{n}$ & $\%$ & $\mathbf{n}$ & $\%$ & $\mathbf{n}$ & $\%$ \\
\hline Cleft Palate & 22 & 6.9 & 32 & 10.1 & 54 & 17.0 \\
\hline Cleft Lip & 19 & 6.0 & 55 & 17.4 & 74 & 23.4 \\
\hline Cleft Lip and Palate & 51 & 16.1 & 138 & 43.5 & 189 & 59.6 \\
\hline Total & $\mathbf{9 2}$ & $\mathbf{2 9 . 0}$ & $\mathbf{2 2 5}$ & $\mathbf{7 1 . 0}$ & $\mathbf{3 1 7}$ & $\mathbf{1 0 0}$ \\
\hline
\end{tabular}

*Chi-square test

$p=0.112$

by CP $(6.9 \%)$ and CL (6\%)

$(\mathrm{p}=0.112)$.

In Table 3, it is possible to assess the distribution of tooth malposition according to their anatomical location (maxilla or mandible). When evaluating the 144 teeth malposition, it can be observed that most (69.48\%) are located in the mandible. Most mandibular malposition was in the canines $(53.47 \%)$, followed by the second premolars $(6.25 \%)$. In the maxilla (30.54\%), the highest occurrence of malposition was seen in lateral incisors $(9.72 \%)$, followed by the central incisor $(9.03 \%)$.

\section{Discussion}

Certain evidence suggests that the phenotype of NSCL/P is much more complex than commonly believed. For that reason, thorough knowledge of its various possible combinations, especially concerning the cleft extension and presence of dental anomalies in areas outside of the cleft, is important [5]. Out of 317 patients evaluated in the present study, 92 (29\%) presented tooth malposition. This result confirms that dental anomalies in NSCL/P patients are more fre- quent than in healthy Brazilian individuals $[7,18]$. Recently, we found $39.9 \%$ of Brazilian patients with NSCL/P present dental anomalies. Tooth agenesis (47.5\%), impacted tooth $(13.1 \%)$, and microdontia $(12.7 \%)$ were the most common anomalies [8].

Certain authors have related higher frequencies of dental anomalies as the severity of the cleft increased $[5,6,19]$. Our results demonstrated that the frequency of tooth malposition was higher in patients with CLP compared to those with CP and CL. Menezes and Vieira (2008) have shown that patients with CP were significantly more affected by dental anomalies than patients with CL or CLP, whereas a series of studies demonstrated a higher frequency of dental anomalies in patients with CLP $[5,20,21]$. In contrast to tooth agenesis, no genetic etiology has yet been established in the case of malposition, although it has been suggested that canine malposition is associated with agenesis and other dental anomalies in populations without oral clefts [22].

In an extensive study with Brazilian patients with NSCL/P, Letra et al., (2007) showed that the mandibular canines were the teeth most commonly affected by malposition associated with CLP. In the present study, there was a higher prevalence of tooth malposition in the mandible compared to the maxilla $(\mathrm{p}<0.01)$. Similar to the study mentioned above [5], the mandibular canines were the most affected teeth $(53.47 \%)$. The observation of malposition, with mandibular canines being the most affected teeth and often associated with CLP, is noteworthy and has not yet been described [5]. Our results agree with these findings. Although the occurrence of tooth malposition could be explained as a consequence of plastic surgery for repair of the oral clefts, which can affect the development of maxillary bone resulting in less space in the upper arch for normal eruption of teeth [23], it is interesting to mention that the higher incidence of this dental anomaly occurred in the mandible and not the maxilla. 


\section{Table 3. Frequency of malposition according to type of tooth in individuals with oral clefts.}

\begin{tabular}{|c|c|c|c|}
\hline Localization & Tooth & $\mathbf{n}$ & $\%$ \\
\hline \multirow{4}{*}{ Mandible } & Central incisors & 2 & 1.39 \\
\hline & Lateral incisors & 6 & 4.2 \\
\hline & Canines & 77 & 53.47 \\
\hline & First premolars & 6 & 4.17 \\
\hline & \multirow{2}{*}{ Second premolars } & 9 & 6.25 \\
\hline & & 100 & 69.48 \\
\hline \multirow{5}{*}{ Maxilla } & Central incisors & 13 & 9.03 \\
\hline & Lateral incisors & 14 & 9.72 \\
\hline & Canines & 12 & 8.33 \\
\hline & \multirow{2}{*}{ First premolars } & 5 & 3.47 \\
\hline & & 44 & 30.54 \\
\hline \multicolumn{2}{|l|}{ Total } & 144 & 100 \\
\hline${ }^{*} \mathrm{Chi}$ & .01 & & \\
\hline
\end{tabular}

When analyzing the cleft type distribution by gender, we found a higher prevalence in males, mainly in CLP, and a higher prevalence of isolated CP in females. These results are concordant with previous studies [6,23-25]. Previous reports have established that oral clefts present a sexual dimorphism: CLP is more common in males and $\mathrm{CP}$ is prevalent in females $[3,7,25]$. Here our results are similar to those found in the literature, but the occurrence of CL isolated was equal in both genders.

As the Brazilian population is result of the genetic admixture of three main ancestral populations (Europeans, Africans, and Amerindians) and displays very high levels of genomic diversity [26], we have previously demonstrated that the use of ancestry markers in associa- tion studies of ethnically mixed populations (structuration of the samples) is important to avoid interpretation bias $[27,28]$. In this study, the characteristics of the ancestry of the studied population (Minas Gerais State, Brazil) were previously evaluated [29].

Few studies have investigated the prevalence of tooth malposition in individuals with NSCL/P. Our results confirmed the highest occurrence of dental anomalies, particularly tooth malposition, in patients with oral clefts. Our study also highlights that there was a higher occurrence of this condition in the mandible and not maxilla. However, future studies are necessary to determine the exact mechanisms responsible for the occurrence of tooth malposition.

\section{Acknowledgments}

This work was partially supported by The Minas Gerais State Research FoundationFAPEMIG, Minas Gerais, Brazil and the Procad/CasadinhoCNPq/CAPES, Brasília, Brazil. 


\section{References}

1. Folate and the face: evaluating the evidence for the influence of folate genes on craniofacial development. Prescott NJ, Malcolm S. Cleft Palate Craniofac J. 2002 May;39(3):327-31. PMID: 12019010.

2. Cleft lip and palate: Understanding genetic and environmental influences. Dixon MJ, Marazita ML, Beaty TH, Murray JC. Nat Rev Genet. 2011 Mar;12(3):167-78. PMID: 21331089.

3. Prevalence of nonsyndromic oral clefts in a reference hospital in the state of Minas Gerais, Brazil, between 2000-2005. Martelli-Junior H, Porto LV, Martelli DR, Bonan PRF, Freitas AB, Coletta RD. Braz Oral Res. 2007 Oct-Dec;21(4):314-7. PMID: 18060257.

4. Epidemiology of Hoffmeister's "Genetically Determined Predisposition to Disturbed Development of the Dentition" in Patients with Cleft Lip and Palate. Stahl F, Grabowski R, Wigger K. Cleft Palate Craniofac J. 2006 Jul;43(4):457-65. PMID: 16854204 .

5. Defining subphenotypes for oral clefts based on dental development. Letra A, Menezes R, Granjeiro JM, Vieira AR. J Dent Res. 2007 Oct;86(10):986-91. PMDI: 17890676.

6. Dental anomalies as part of the cleft spectrum. Menezes R, Vieira AR. Cleft Palate Craniofac J. 2008 Jul;45(4):414-9. PMID: 18616370.
7. Side of dental anomalies and taurodontism as potential clinical markers for cleft subphenotypes. Kuchler E, Motta L, Vieira A, Granjeiro J. Cleft Palate Craniofac J. 2011 Jan;48(1):103-8. PMID: 20507240.

8. Prevalence of Dental Anomalies in Patients With Nonsyndromic Cleft Lip and/or Palate in a Brazilian Population. Paranaíba LMR, Coletta RD, Swerts MSO. Quintino RP, Barros LM, Martelli-Júnior H. Cleft

Palate Craniofac J. 2013

Jul;50(4):400-5. PMID: 21973329.

9. Expanding the cleft phenotype cleft l: the dental characteristics of unaffected parents of Australian children with non-syndromic lip and palate. Aspinall A, Raj S, Jugessur A, Marazita M, Savarirayan R, Kilpatrick N. Int J Paediatr Dent. 2014 Jul;24(4):286-92. PMID: 24237197.

10. Identification of cell patterns in human tooth differentiation. Tonge CH. J Dent Res. 1967 SepOct;46(5):876-8. PMID: 5234028.

11. The many faces and factors of orofacial clefts. Schutte BC, Murray JC. Hum Mol Genet. 1999;8(10):1853-9. PMID: 10469837.

12. The origin and development of the upper lateral incisor and premaxilla in normal and cleft lip/palate monkeys induced with cyclophosphamide. Wei X, Senders C, Owiti GO, Liu X, Wei ZN, DillardTelm L. Cleft Palate Craniofac J. 2000 Nov;37(6):571-83. PMID: 11108527.
13. Abnormalities of the maxillary incisors in children with cleft lip and palate. Vichi M, Franchi L. ASDC J Dent Child. 1995 NovDec;62(6):412-7. PMID: 8636477.

14. Dental anomalies of number in the permanent dentition of patients with bilateral cleft lip: radiographic study. da Silva AP, Costa B, de Carvalho Carrara CF. Cleft Palate Craniofac J. 2008 Sep;45(5):473-6. PMID: 8788864.

15. Distribution patterns of primary and permanent dentition in children with unilateral complete cleft lip and palate. Tsai TP, Huang CS, Huang CC, See LC. Cleft Palate Craniofac J. 1998 Mar;35(2):154-60. PMID: 9527312.

16. Prevalence and distribution of selected developmental dental anomalies in an Indian population. Gupta SK, Saxena P, Jain S, Jain D. J Oral Sci. 2011 Jun;53(2):231-8. PMID: 21712629.

17. Classification of cleft lip and cleft palate. Suggested changes. Spina V, Psillakis JM, Lapa FS, Ferreira MC. Rev Hosp Clin Fac Med São Paulo. 1972 Jan-Feb;27(1):5-6. PMID: 4671376.

18. Studies of dental anomalies in a large group of school children. Kuchler EC, Risso PA, Costa Mde C, Modesto A, Vieira AR. Arch Oral Biol. 2008 Oct;53(10):941-6. PMID: 18490001.

19. Prevalence of dental anomalies in a population of cleft lip and palate patients. Al Jamal GA, Hazza'a AM, Rawashdeh MA. Cleft Palate 
Craniofac J. 2010 Jul;47(4):413-20. PMID: 20590463.

20. Hypodontia in children with various types of clefts. Shapira $Y$, Lubit E, Kuftinec MM. Angle Orthod. 2000 Feb;70(1):16-21. PMID: 10730671.

21. Genetic association studies of cleft lip and/or palate with tooth hypodontia outside the cleft region. Slayton RL, Williams L, Murray JC, Wheeler JJ, Lidral AC, Nishimura CJ. Cleft Palate Craniofac J. 2003

May;40(3):274-9. PMID: 12733956.

22. Concomitant occurrence of canine malposition and tooth agenesis: evidence of orofacial genetic fields. Peck S, Peck L, Kataja M. Am J Orthod Dentofacial Orthop. 2002 Dec;122(6):657-60. PMID: 12490878.

23. Dental anomalies in children born with clefts: a case-control study. de Lima Pedro R, Faria MDB, Costa MC, Vieira AR. Cleft Palate Craniofac J. 2012 Nov; 49(6):e64-e8. PMID: 21740171.

24. Classification and birth prevalence of orofacial clefts. Tolarová TT, Cervenka J. Am J Med Genet. 1998 Jan;75(2):126-37. PMID:

9450872.

25. Orofacial cleft in Southern Italy. Carinci F, Rullo R, Laino G, Festa V, Mazzarella N, Morano D, Gombos F. Minerva Stomatol. 2003

Oct;52(10):427-3. PMID: 14765027.

26 . The genomic ancestry of individuals from different geographical regions of Brazil is more uniform than expected. Pena SD, Di Pietro G,
Fuchshuber-Moraes M, Genro JP, Hutz MH, Kehdy Fde S, Kohlrausch F, Magno LA, Montenegro RC, Moraes MO, de Moraes ME, de Moraes MR, Ojopi EB, Perini JA, Racciopi C, Ribeiro-Dos-Santos AK, Rios-Santos F, Romano-Silva MA, Sortica VA, Suarez-Kurtz G. PLoS One. 2011 Feb;6(2):e17063. PMID: 21359226.

27. Polymorphisms at regions 1p22.1 (rs560426) and 8q24 (rs1530300) are risk markers for nonsyndromic cleft lip and/or palate in the Brazilian population. Bagordakis E, Paranaiba LM, Brito LA, de Aquino SN, Messetti AC, MartelliJunior H, Swerts MS, Graner E, Passos-Bueno MR, Coletta RD. Am J Med Genet A. 2013 May;161A(5):1177-80. PMID: 23532876.

28. Polymorphisms in FGF12, VCL, CX43 and VAX1 in Brazilian patients with nonsyndromic cleft lip with or without cleft palate. de Aquino SN, Messetti AC, Bagordakis E, MartelliJúnior H, Swerts MS, Graner E, Coletta RD. BMC Med Genet. 2013 May;14:53-6. PMID: 23679094.

29. Analysis of susceptibility polymorphisms for nonsyndromic cleft lip with or without cleft palate in the Brazilian population. Birth Defects. de Aquino SN, Messetti AC, Hoshi R, Borges A, Viena CS, Reis SR, Oliveira Swerts MS, Graner E, Martelli-Júnior H, Coletta RD. Res A Clin Mol Teratol. 2014 Jan;100(1):36-42. PMID: 24446087. 